\title{
Symptomatic hypercalcaemia in paediatric tuberculosis
}

\section{To the Editor:}

A 13-yr-old Congolese female presented in early spring with a 6-month history of productive cough, progressive exertional dyspnoea and weight loss of $4.5 \mathrm{~kg}$. 2 weeks prior to presentation she had developed high fevers and increasing lethargy. She had immigrated to the UK at the age of 2 yrs. She had not been overseas since and there was no history of contact with anyone with tuberculosis (TB). She had no past medical history and was fully immunised except for bacilli Calmette-Guérin.

On examination she was cachectic and lethargic. There were no signs of clubbing, rickets or oedema. Her weight was $34 \mathrm{~kg}$ (less than third centile), height $148 \mathrm{~cm}$ (10th centile) and body mass index $15 \mathrm{~kg} \cdot \mathrm{m}^{-2}$ (less than first centile). She was tachycardic and tachypnoeic with oxygen saturations of $90 \%$ in air. There was dullness to percussion and widespread coarse crackles on auscultation throughout the left lung field and at the right apex. The chest radiograph showed extensive left lung and right upper lobe consolidation (fig. 1). Her C-reactive protein was $160 \mathrm{mg} \cdot \mathrm{L}^{-1}$ and erythrocyte sedimentation rate was $90 \mathrm{~mm} \cdot \mathrm{h}^{-1}$. Her corrected calcium and phosphate were low, $1.96 \mathrm{mmol} \cdot \mathrm{L}^{-1}$ (normal range $2.18-2.47 \mathrm{mmol} \cdot \mathrm{L}^{-1}$ ) and $0.80 \mathrm{mmol} \cdot \mathrm{L}^{-1}\left(0.75-1.50 \mathrm{mmol} \cdot \mathrm{L}^{-1}\right)$, respectively, with albumin and alkaline phosphatase levels of $23 \mathrm{~g} \cdot \mathrm{L}^{-1}\left(35-40 \mathrm{~g} \cdot \mathrm{L}^{-1}\right)$ and $118 \mathrm{mmol} \cdot \mathrm{L}^{-1}\left(30-200 \mathrm{mmol} \cdot \mathrm{L}^{-1}\right)$, respectively. Her Mantoux test was strongly positive (20 $\mathrm{mm}$ induration) and acid-fast bacilli were present in her sputum, which subsequently cultured Mycobacterium tuberculosis. In addition to consolidation, her chest computed tomography scan showed cavities within the distal bronchi, widespread tree-in-bud appearances throughout the left lower lobe and extensive mediastinal, paratracheal and subcarinal adenopathy. Standard quadruple anti-tuberculous therapy (isoniazid, rifampicin, ethambutol and pyrazinamide) was started. In view of her malnutrition, nasogastric (NG) tube feeds were also commenced. Her serum 25-hydroxy-vitamin $\mathrm{D}_{3}$ level, taken prior to starting antituberculous therapy, was low at $20 \mathrm{nmol} \cdot \mathrm{L}^{-1}$ (normal range $\left.75-200 \mathrm{nmol} \cdot \mathrm{L}^{-1}\right)$, therefore supplementation with ergocalciferol (vitamin $\mathrm{D}_{2}$ ) 10,000 IU $\cdot$ day $^{-1}$ was initiated. On discharge from hospital 20 days later her serum calcium was within the normal range.

1 week later she represented with nausea and vomiting, abdominal pain and aching muscles. Her respiratory symptoms had improved but she was continuing to lose weight and appeared very low in mood. Her serum calcium level was very high at $3.74 \mathrm{mmol} \cdot \mathrm{L}^{-1}$, with phosphate and albumin levels of $1.60 \mathrm{mmol} \cdot \mathrm{L}^{-1}$ and $33 \mathrm{~g} \cdot \mathrm{L}^{-1}$, respectively. Urinary calcium was high at $7.82 \mathrm{mmol} \cdot \mathrm{L}^{-1}\left(1.87-3.39 \mathrm{mmol} \cdot \mathrm{L}^{-1}\right)$, although her renal function tests were normal. The 1,25-dihydroxy-vitamin $\mathrm{D}_{3}$ level was also high at $311 \mathrm{pmol} \cdot \mathrm{L}^{-1}\left(40-150 \mathrm{pmol} \cdot \mathrm{L}^{-1}\right)$. Her parathyroid hormone was low at $<0.7 \mathrm{pmol} \cdot \mathrm{L}^{-1}\left(1.1-6.9 \mathrm{pmol} \cdot \mathrm{L}^{-1}\right)$ and 25-hydroxy-vitamin $\mathrm{D}_{3}$ was normal at $144 \mathrm{nmol} \cdot \mathrm{L}^{-1}(75-$ $200 \mathrm{nmol} \cdot \mathrm{L}^{-1}$ ). The ergocalciferol supplements, which she had been taking for 28 days, were stopped and NG feeding was restarted with reduced calcium. Her symptoms of hypercalcaemia improved rapidly but serum calcium remained high so she was started on intravenous fluids. Her serum calcium gradually decreased over several days. 3 months later she remains on anti-tuberculous treatment and the hypercalcaemia has not recurred.

The two sources of vitamin D in humans are metabolism in the skin in response to sunlight, and ingestion and absorption via the intestine (fig. 1). Vitamin $\mathrm{D}_{3}$ (cholecalciferol; the most abundant form) is partially hydroxylated in the liver to form 25-hydroxy-vitamin $\mathrm{D}_{3}\left(25(\mathrm{OH}) \mathrm{D}_{3}\right.$; calcidiol) which is then further hydroxylated in the kidney to form 1,25-dihydroxyvitamin $\mathrm{D}_{3}\left(1,25(\mathrm{OH})_{2} \mathrm{D}_{3}\right.$; calcitriol). The latter is the active form of vitamin $D_{3}$ which causes increased gastrointestinal absorption of calcium, osteoclastic resorption from bone and renal tubular resorption, raising serum calcium levels. In addition, vitamin D inhibits parathyroid hormone which regulates serum calcium levels.

Hypercalcaemia has been described in adult patients with most granulomatous disorders, including $\mathrm{TB}$, although the majority are asymptomatic. Rates of hypercalcaemia in TB in adults vary widely from 6 to $48 \%$ [1, 2]. Symptomatic hypercalcaemia in TB is less common, with rates of $\sim 3 \%$ in adults [3], although there are no data in children. Allowing for variation in methodology, differences between populations are probably due to sun exposure and diet, particularly the latter.

Attempts to predict which patients will develop hypercalcaemia have been unsuccessful as there is no clear relationship between serum calcium level and type or stage of disease: some patients are hypercalcaemic at diagnosis, while others develop hypercalcaemia while on treatment. In addition, there is discrepancy between studies correlating serum calcium levels and radiological extent of disease, with some finding an association and others finding no relationship.

There are only a few cases in the literature over the last 25 yrs which have reported children with hypercalcaemia associated with TB, often with severe disease (table 1) [4-10]. Our case describes a teenage female with extensive pulmonary $\mathrm{TB}$ associated with symptomatic hypercalcaemia that persisted despite cessation of vitamin D supplementation. It is the first report of symptomatic hypercalcaemia in a child on both antituberculous therapy and vitamin D supplementation. 


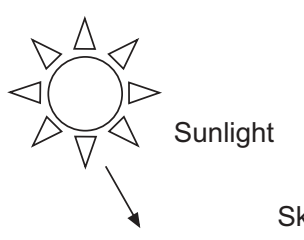

Skin Liver Kidney

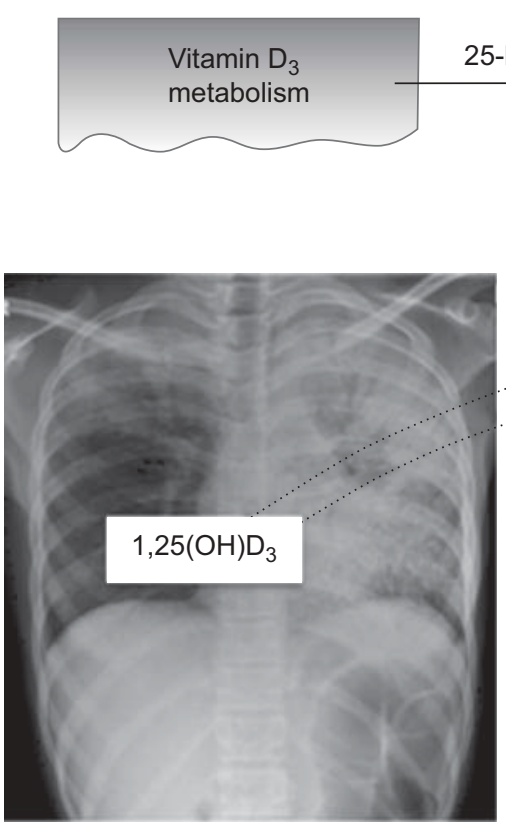

Extrarenal production

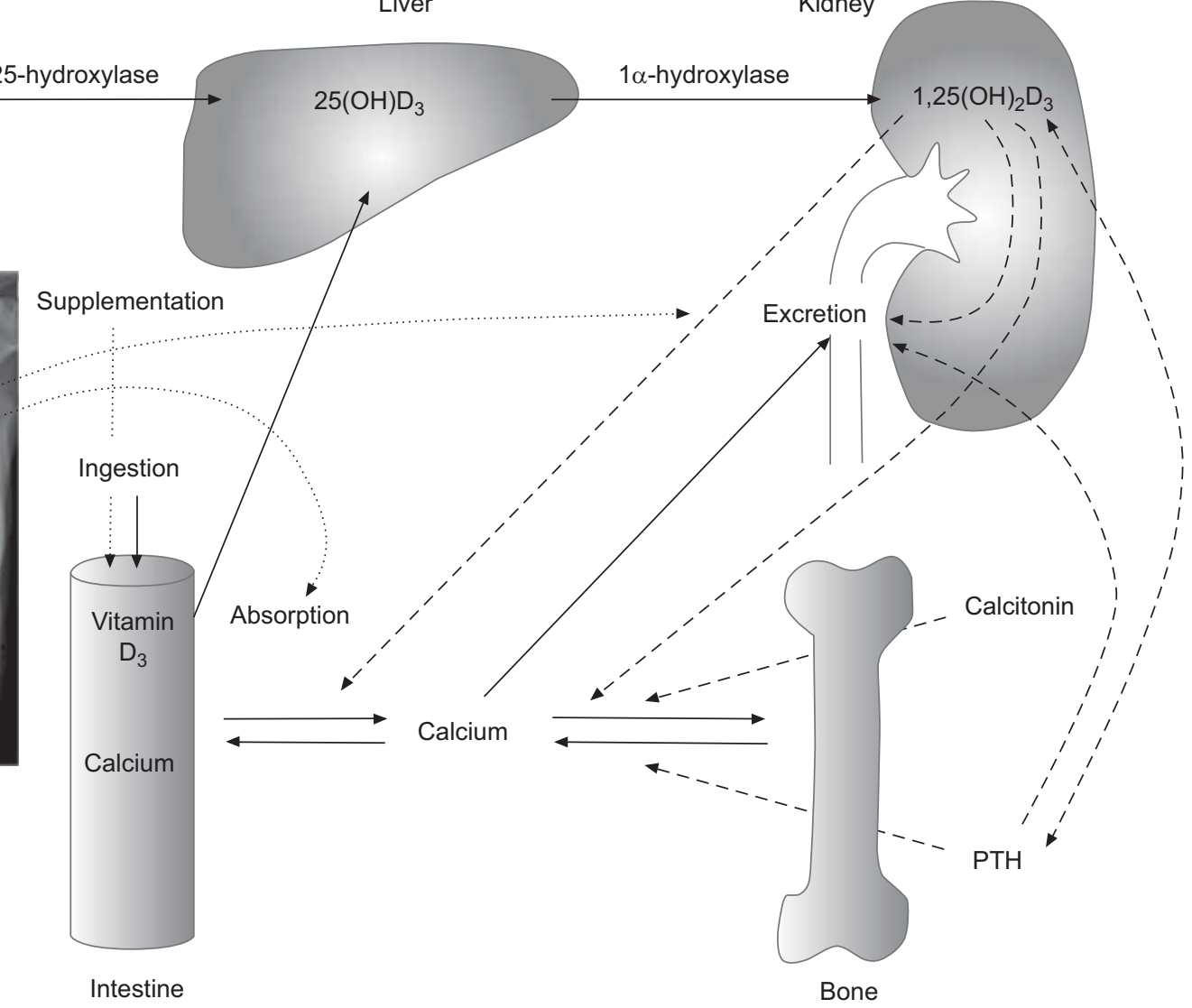

FIGURE 1. Calcium and vitamin D metabolism. Continuous arrows represent movement of calcium and vitamin $D$ and its metabolites. Dashed arrows represent the effects of vitamin $D$ and hormones on calcium. Dotted arrows represent potential mechanisms of hypercalcaemia in tuberculosis. The chest radiography of our patient is included and shows extensive pulmonary consolidation and lack of subcutaneous tissue. PTH: parathyroid hormone.

The mechanism underlying hypercalcaemia in TB is thought to be over-production of $1,25(\mathrm{OH})_{2} \mathrm{D}_{3}$ in extra-renal macrophages in granulomas, for example in the alveoli. It has been suggested that the production of $1,25(\mathrm{OH})_{2} \mathrm{D}_{3}$ has a protective effect against oxidative injuries from the nitric oxide burst from granulomatous macrophages [11]. This was initially studied in other granulomatous diseases, such as sarcoidosis. In TB, $1,25(\mathrm{OH})_{2} \mathrm{D}_{3}$ has been shown to be produced by alveolar macrophages from a patient with pulmonary TB [12], and high serum levels have been found in anephric patients, further supporting an extra-renal source [13]. Because production is extra-renal, the normal feedback control of $1,25(\mathrm{OH})_{2} \mathrm{D}_{3}$ production by parathyroid hormone is ineffective.

However, TB-associated hypercalcaemia has also been reported in patients with normal [4] and low [14] levels of serum $1,25(\mathrm{OH})_{2} \mathrm{D}_{3}$. Other causes may include an overdose of vitamin D or calcium supplements. An alternative possibility is abnormal activation of parathyroid hormone-related protein, which is the usual aetiological agent of hypercalcaemia of malignancy and is raised in some patients with sarcoidosis [15].
Recent studies have focussed on the association between low vitamin D levels and active TB [16]. However, despite investigation of vitamin D levels and supplementation becoming increasingly common in clinical practice, the mechanism is not fully understood. This case raises the possibility that extrarenal production of $1,25(\mathrm{OH})_{2} \mathrm{D}_{3}$ in $\mathrm{TB}$ may inappropriately lower serum $25(\mathrm{OH}) \mathrm{D}_{3}$ resulting in, or at least contributing to, this finding.

It is likely that the hypercalcaemia in our patient was multifactorial. Normal $25(\mathrm{OH}) \mathrm{D}_{3}$ and high $1,25(\mathrm{OH})_{2} \mathrm{D}_{3}$ indicate that the hypercalcaemia was secondary to granulomatous disease rather than vitamin D toxicity. However, the fact that our patient was not hypercalcaemic at presentation suggests that it may not have been due to disease alone. The vitamin D supplementation would have increased calcium absorption from the intestine at the same time as she was receiving highly nutritious NG feeds. It is likely that this, in combination with extra-renal $1,25(\mathrm{OH})_{2} \mathrm{D}_{3}$ production, explains her hypercalcaemic state.

The management of hypercalcaemia in TB involves treatment of the underlying cause, together with measures to reduce the 


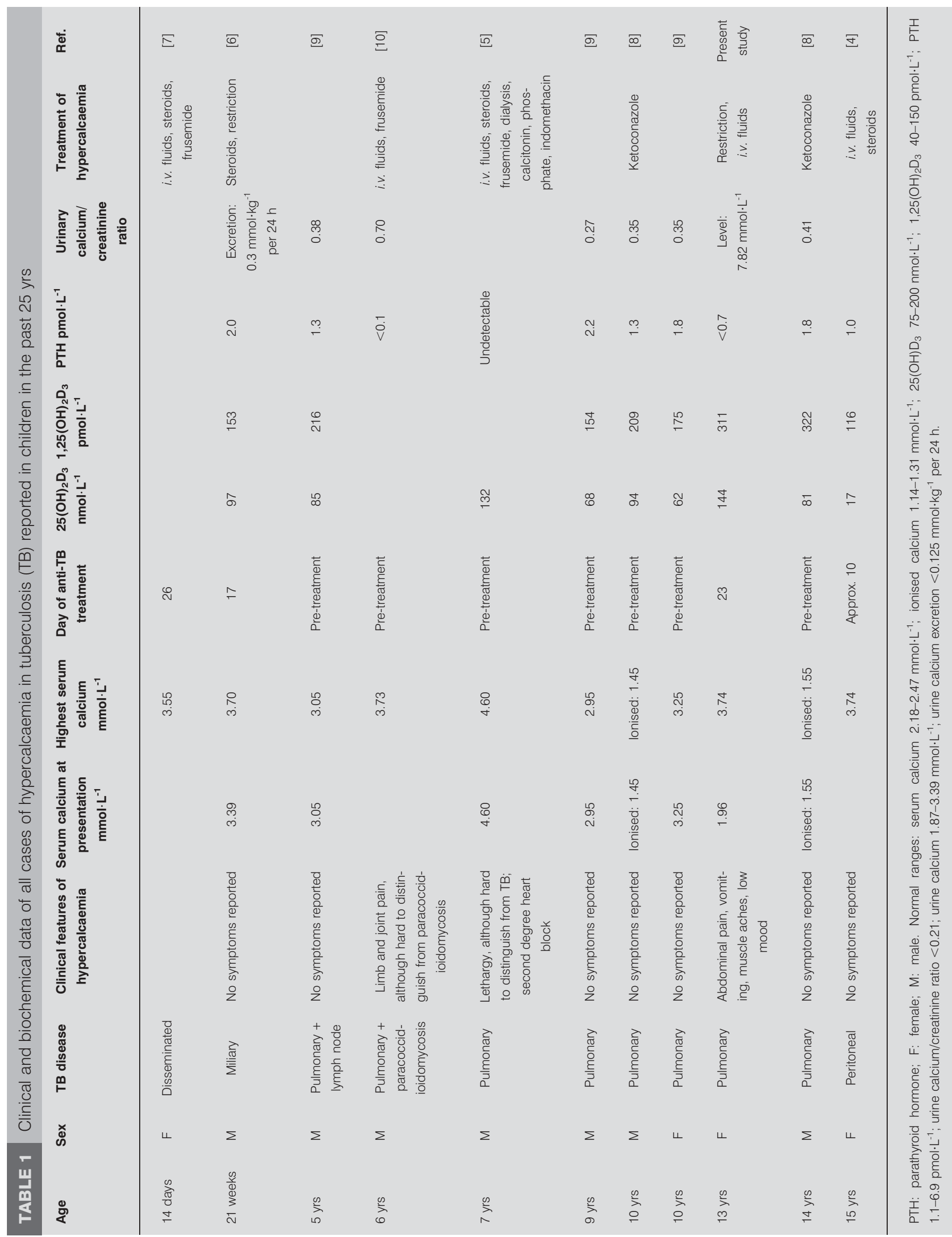


serum calcium. Restriction of calcium and vitamin D supplements is sometimes all that is required, although intravenous fluids may be used for more rapid normalisation of serum levels. A variety of other treatments have been used: ketoconazole, hydroxychloroquine, bisphosphanates and corticosteroids $[6,8,17]$. The mechanisms for these therapeutic measures are not fully understood, although corticosteroids are believed to reduce the concentration of $1,25(\mathrm{OH})_{2} \mathrm{D}_{3}$ by inhibiting hydroxylation to this metabolite [16]. Unless absolutely necessary, polypharmacy should be avoided as patients already have a significant medication burden and additional medications may affect compliance. In our case supplement restriction and intravenous hydration was sufficient.

Our case illustrates the infrequently recognised and poorly understood phenomenon of hypercalcaemia in TB. Children with TB are increasingly being tested and treated for vitamin D deficiency. However, there are no clear guidelines for dosage and duration of supplementation, and further studies are needed to address this. It is therefore important to monitor serum calcium and vitamin D levels especially after starting concurrent supplementation and nutrition, and to have a high index of suspicion for hypercalcaemia when presented with gastrointestinal or musculoskeletal symptoms.

\section{H.A. Payne*, E. Menson", M. Sharland* and P.A. Bryant*} *Dept of Paediatric Infectious Diseases, St Georges Healthcare NHS Trust, and "Dept of Paediatrics, The Evelina Children's Hospital, London, UK.

Correspondence: H. Payne, Paediatric Infectious Diseases, St Georges Healthcare NHS Trust, Blackshaw Road, London, SW17 0QT, London, UK. E-mail: helenpayne@doctors.org.uk

Statement of Interest: None declared.

Provenance: Submitted article, peer reviewed.

\section{REFERENCES}

1 Chan TY, Chan CH, Shek CC. The prevalence of hypercalcaemia in pulmonary and miliary tuberculosis: a longitudinal study. Singapore Med J 1994; 35: 613-615.

2 Kitrou MP, Phytou-Pallikari A, Tzannes SE, et al. Serum calcium during chemotherapy for active pulmonary tuberculosis. Eur J Respir Dis 1983; 64: 347-354.
3 Roussos A, Lagogianni I, Gonis A, et al. Hypercalcaemia in Greek patients with tuberculosis before the initiation of anti-tuberculosis treatment. Respir Med 2001; 95: 187-190.

4 Ayonrinde OT, Zimmerman MJ. Ascites, hypercalcaemia, diffuse peritoneal thickening and elevated OM-MA in a fifteen-year-old girl (a case of peritoneal tuberculosis). Intern Med J 2004; 34: 216-217.

5 Gaskin KJ, Vines RH. Hypercalcaemia: an unusual complication of tuberculosis. A case report. Aust Paediatr J 1978; 14: 44-47.

6 Gerritsen J, Knol K. Hypercalcaemia in a child with miliary tuberculosis. Eur J Pediatr 1989; 148: 650-651.

7 Okascharoen C, Nuntnarumit P, Sirinavin S. Neonatal tuberculosis associated with shock, disseminated intravascular coagulation, hemophagocytic syndrome, and hypercalcemia: a case report. J Perinatol 2003; 23: 79-81.

8 Saggese G, Bertelloni S, Baroncelli GI, et al. Ketoconazole decreases the serum ionized calcium and 1,25-dihydroxyvitamin D levels in tuberculosis-associated hypercalcemia. Am J Dis Child 1993; 147: 270-273.

9 Saggese G, Bertelloni S, Baroncelli GI, et al. [Abnormal synthesis of 1,25-dihydroxyvitamin D and hypercalcemia in children with tuberculosis]. Pediatr Med Chir 1989; 11: 529-532.

10 Tresoldi AT, Pereira RM, Castro LC, et al. [Hypercalcemia and multiple osteolytic lesions in a child with disseminated paracoccidioidomycosis and pulmonary tuberculosis]. J Pediatr (Rio J) 2005; 81: 349-352.

11 Chang JM, Kuo MC, Kuo HT, et al. 1-alpha,25-Dihydroxyvitamin D3 regulates inducible nitric oxide synthase messenger RNA expression and nitric oxide release in macrophage-like RAW 264.7 cells. J Lab Clin Med 2004; 143: 14-22.

12 Cadranel J, Hance AJ, Millerson B, et al. Vitamin D metabolism in tuberculosis: production of $1,25(\mathrm{OH})_{2} \mathrm{D}_{3}$ by cells recovered from bronchoalveolar lavage and the role of this metabolite in calcium homeostasis. Am Rev Respir Dis 1988; 138: 984-989.

13 Gkonos PJ, London R, Hendler ED. Hypercalcaemia and elevated 1.25-dihydroxyvitamin $\mathrm{D}$ levels in a patient with end-stage renal disease and active tuberculosis. N Engl J Med 1984; 311: 1683-1685.

14 Meuthen I, Kirsch L, Saborowski F. [Hypercalcemia in florid pulmonary and cervical lymph node tuberculosis]. Dtsch Med Wochenschr 1991; 116: 899-902.

15 Zeimer HJ, Greenaway TM, Slavin J, et al. Parathyroid-hormonerelated protein in sarcoidosis. Am J Pathol 1998; 152: 17-21.

16 Nnoaham KE, Clarke A. Low serum vitamin D levels and tuberculosis: a systematic review and meta-analysis. Int $J$ Epidemiol 2008; 37: 113-119.

17 Isaacs RD, Nicholson GI, Holdaway IM. Miliary tuberculosis with hypercalcaemia and raised vitamin D concentrations. Thorax 1987; 42: 555-556.

\section{A 69-year-old female with multiple, bilateral pulmonary nodules}

\section{To the Editor:}

A 69-yr-old post-menopausal female with pulmonary nodules and a diagnosis of lymphangioleiomyomatosis (LAM) confirmed elsewhere was referred to our centre (U.O. di Pneumologia, Ospedale San Giuseppe, Milan, Italy) for further evaluation.
The patient was a nonsmoker and denied any occupational exposures. There was no family history of cancer. She had no history of pulmonary diseases or respiratory symptoms. Her past medical history included systemic hypertension treated with angiotensin converting enzyme inhibitor, hypercholesterolemia treated with atorvastatin, and diabetes mellitus. The patient had 